\title{
KANK1-NTRK3 fusions define a subset of BRAF mutation negative renal metanephric adenomas
}

\author{
Aida Catic ${ }^{1,2^{*}}$ (D), Amina Kurtovic-Kozaric ${ }^{2,3}$, Ardis Sophian ${ }^{1}$, Lech Mazur ${ }^{1}$, Faruk Skenderi ${ }^{3}$, Ondrej Hes ${ }^{4}$, \\ Stephen Rohan ${ }^{5}$, Dinesh Rakheja ${ }^{6,7}$, Jillene Kogan ${ }^{1,8,9,10}$ and Michael R. Pins ${ }^{8,9}$
}

\begin{abstract}
Background: Metanephric adenoma (MA) is a rare benign renal neoplasm. On occasion, MA can be difficult to differentiate from renal malignancies such as papillary renal cell carcinoma in adults and Wilmś tumor in children. Despite recent advancements in tumor genomics, there is limited data available regarding the genetic alterations characteristic of MA. The purpose of this study is to determine the frequency of metanephric adenoma cases exhibiting cytogenetic aberration t $(9 ; 15)($ p24;q24), and to investigate the association between $\mathrm{t}(9,15)$ and BRAF mutation in metanephric adenoma.

Methods: This study was conducted on 28 archival formalin fixed paraffin-embedded (FFPE) specimens from patients with pathologically confirmed MA. Tissue blocks were selected for BRAF sequencing and fluorescent in situ hybridization (FISH) analysis for chromosomal rearrangement between KANK1 on chromosome 9 (9p24.3) and NTRK3 on chromosome 15 (15q25.3), which was previously characterized and described in two MA cases.

Results: $B R A F^{\mathrm{V} 600 \mathrm{E}}$ mutation was identified in $62 \%$ of our cases, $9(38 \%)$ cases were BRAF ${ }^{\mathrm{WT}}$, and 4 cases were uninformative. Of the 20 tumors with FISH results, two (10\%) were positive for KANK1-NTRK3 fusion. Both cases were $B R A F^{\mathrm{WT}}$ suggesting mutual exclusivity of BRAF ${ }^{V 600 E}$ and KANK1-NTRK3 fusion, the first such observation in the literature.

Conclusions: Our data shows that BRAF mutation in MA may not be as frequent as suggested in the literature and KANK-NTRK3 fusions may account for a subset of $B R A F^{W T}$ cases in younger patients. FISH analysis for KANK1-NTRK3 fusion or conventional cytogenetic analysis may be warranted to establish the diagnosis of MA in morphologically and immunohistochemically ambiguous MA cases lacking BRAF mutations.
\end{abstract}

Keywords: Metanephric adenoma, Cytogenetics, Chromosomal translocations, KANK1-NTRK3 fusion, BRAF $F^{\text {V600E }}$

\section{Background}

Metanephric adenoma (MA) is a rare benign renal tumor classified under the rubric of metanephric tumors, which also include metanephric stromal tumor and metanephric adenofibroma [1]. BRAF mutations

\footnotetext{
* Correspondence: aida.catic.00@gmail.com

'Department of Cytogenetics, ACL Laboratories, Rosemont, IL, USA

${ }^{2}$ Department of Genetics and Bioengineering, International Burch University, Francuske revolucije bb, llidza, 71000 Sarajevo, Bosnia and Herzegovina Full list of author information is available at the end of the article
}

have been identified in metanephric stromal tumor and metanephric adenofibroma in addition to metanephric adenoma, which justifies their grouping as family of metanephric tumors by the World Health Organization (WHO) [2]. MA is uncommon and generally occurs in adults between the fourth and sixth decades of life and occasionally in children [3]. The male-to-female ratio is between 1:2 to $1: 3$ with a mean age of approximately 41 years $[3,4]$. In adults, MA accounts for approximately $0.2 \%$ of adult renal epithelial neoplasms [5]. Despite the

(c) The Author(s). 2020 Open Access This article is licensed under a Creative Commons Attribution 4.0 International License, which permits use, sharing, adaptation, distribution and reproduction in any medium or format, as long as you give appropriate credit to the original author(s) and the source, provide a link to the Creative Commons licence, and indicate if changes were made. The images or other third party material in this article are included in the article's Creative Commons licence, unless indicated otherwise in a credit line to the material. If material is not included in the article's Creative Commons licence and your intended use is not permitted by statutory regulation or exceeds the permitted use, you will need to obtain permission directly from the copyright holder. To view a copy of this licence, visit http://creativecommons.org/licenses/by/4.0/ The Creative Commons Public Domain Dedication waiver (http://creativecommons.org/publicdomain/zero/1.0/) applies to the data made available in this article, unless otherwise stated in a credit line to the data. 
fact that fewer than 25 cases have been reported in children, it is considered to be the most common benign pediatric renal epithelial tumor [6, 7]. Including both pediatric and adult cases, fewer than 200 cases of MA have been reported in the literature, thus, illustrating its rarity and the scarcity of available data [5-8].

The majority of MA cases can be diagnosed on routine hematoxylin and eosin $(\mathrm{H} \& \mathrm{E})$ stained slides. However, in some challenging cases MA can be difficult to morphologically differentiate from malignant renal neoplasms [9]; particularly the solid variant of papillary renal cell carcinoma (PRCC) and epithelial-predominant Wilms' tumor (WT) [10]. The distinction between these renal tumor subtypes can be aided by the use of diagnostic modalities such as immunohistochemistry, cytogenetic studies, and advanced molecular analyses [3]. The correct classification of a renal tumor is not only critical from a diagnostic standpoint, but also from a prognostic and therapeutic standpoint $[11,12]$.

Immunohistochemistry may be helpful in distinguishing metanephric adenoma from solid variant of papillary renal cell carcinoma (s-pRCC) and epithelial predominant Wilm's tumor (e-WT). Specifically, MAs are generally diffusely CD57 and WT1 positive, only focally CK7 positive, and CD56 and AMACR negative (rarely weakly positive), s-pRCCs are generally diffusely CK7 and AMACR positive, often CD57 positive (in contrast to conventional [non solid-variant] pRCC, which is usually CD57 negative) and WT1 and CD56 negative, and eWTs are generally diffusely CD56 and WT1 positive and variably CD57, CK7, and AMACR positive.

The genetic alterations underlying MA tumorigenesis have only been defined relatively recently [11]. Previous cytogenetic studies have revealed a paucity of genetic alterations in MA. The molecular and cytogenetics data reported in the literature in regard to MA is sparse and often consists of literature reviews of previously published cases or isolated case reports. We and another group each reported a case of MA showing a t $(9 ; 15)$ [11-13]. A study by Choueiri et al. demonstrated that approximately $90 \%$ of MAs harbor $B R A F^{\mathrm{V} 600 \mathrm{E}}$ mutations; the genetics of the remaining $10 \%$ in their study is unclear [14]. $B R A F^{\mathrm{V} 600 \mathrm{E}}$ gene mutations are frequently detected in a wide range of benign and malignant human tumors, however, BRAF mutations in renal tumors such as renal cell carcinoma (RCC), oncocytoma, and WT are essentially absent $[4,15-21]$. This data coupled with Choueiri's data suggests that BRAF mutations are specific for MA amongst renal tumors.

The present study was undertaken to determine the frequency of MA cases exhibiting cytogenetic aberration $\mathrm{t}(9 ; 15)(\mathrm{p} 24 ; \mathrm{q} 24)$ as previously reported in the literature, and to investigate the association between $\mathrm{t}(9 ; 15)$ and BRAF mutation in MAs [11-13]. Two cases included in this study have previously been reported in literature (case \# 1 and \#12-Table 1.). Catic et al. have demonstrated the specific gene fusion that results from the chromosomal translocation $t(9,15)(\mathrm{p} 24 ; \mathrm{q} 24)$ [11]. Rakheja et al. reported chromosomal translocation mentioned above with only a karyotype [13]. We examined 28 cases of MA at the genetic and molecular level, using a combination of BRAF sequencing and fluorescent in situ hybridization (FISH) to detect chromosomal rearrangement between KANK1 on chromosome 9 (9p24.3) and NTRK3 on chromosome 15 (15q25.3).

\section{Methods}

\section{Patients and samples}

This study was conducted on 28 archival formalin fixed paraffin-embedded (FFPE) specimens from renal metanephric adenomas. FFPE blocks and H\&E stained slides were obtained from the departments of pathology at four participating institutions, including Advocate Lutheran General Hospital (Park Ridge, IL, USA), Northwestern Memorial Hospital (Chicago, IL, USA), Children's Medical Center of Dallas (Dallas, TX, USA), and Charles University Hospital (Plzen, Czech Republic). Fourteen cases were of American origin and 14 of European origin. All samples received for this study and data reported have been de-identified. Because this was a retrospective study, ethics committee ruled that no formal ethics approval was required in this particular study.

The MA specimens and hematoxylin and eosinstained slides were retrieved and reviewed by expert pathologists at each institution. All pathologic specimens were acquired after partial or complete nephrectomy, and none were diagnosed by needle biopsy. The diagnosis of MA was then re-confirmed by two genitourinary pathologists (Fig. 1) and de-identified representative tissue blocks were further selected for $B R A F^{\mathrm{V} 600 \mathrm{E}}$ exon 15 sequencing and FISH analysis. Histologically, the tumors are composed of epithelial cells arranged in tubules and papillary configurations. The relatively small tumor cells have a high nuclear: cytoplasmic ratio, ovoid nuclei, uniformly dispersed chromatin, inconspicuous nucleoli, scant eosinophilic cytoplasm, and ill-defined cell borders with nuclear overlap, Fig. 1, a and b. Mitoses are not conspicuous. Occasional psammomatoid calcifications are seen, Fig. 2. Patient demographics and clinicopathologic characteristics such as: age, gender, tumor size, laterality, and chromosomal analysis results were provided by pathologists at each institution (Table 1).

\section{Fluorescence in situ hybridization (FISH)}

Metaphase chromosome spreads and interphase nuclei were prepared on a glass microscope slide in accordance with standard cytogenetic procedure and according to the manufacturer's instructions. Paraffin embedded tissue slides were cut at $2-\mu \mathrm{m}$ thickness using a microtome and floated in a protein free waterbath at $40{ }^{\circ} \mathrm{C}$. A 
Table 1 Clinical, pathological, cytogenetic, and molecular findings ${ }^{a}$

\begin{tabular}{|c|c|c|c|c|c|c|c|}
\hline Case no. & Age range years & Gender & Tumor Size $(\mathrm{cm})$ & Laterality & Karyotype & BRAF Status & $t(9 ; 15)(p 24 ; q 24) F I S H$ \\
\hline 1. & $21-30$ & $\mathrm{~F}$ & 2 & Right & $46, X X, t(9 ; 15)(p 24 ; q 24)$ & Wild type & Fusion Present \\
\hline 2. & $21-30$ & $\mathrm{~F}$ & 3 & Left & $46, X X, t(6 ; 22)(q 26 ; q 11.2)$ & Wild type & Normal \\
\hline 3. & $41-50$ & M & 12 & NA & $46, X Y$ & V600E Mutation & Normal \\
\hline 4. & $51-60$ & $\mathrm{~F}$ & 1.4 & Left & $46, X X$ & V600E Mutation & Normal \\
\hline 5. & $51-60$ & M & 3 & Right & $46, X Y$ & V600E Mutation & Normal \\
\hline 6. & $31-40$ & $\mathrm{~F}$ & 6.7 & Left & NA & V600E Mutation & Normal \\
\hline 7. & $61-70$ & $\mathrm{~F}$ & NA & Right & NA & Uninformative & Uninformative \\
\hline 8. & $51-60$ & M & NA & NA & NA & V600E Mutation & Uninformative \\
\hline 9. & $51-60$ & $\mathrm{~F}$ & 0.5 & Right & NA & Uninformative & Uninformative \\
\hline 10. & $61-70$ & $\mathrm{~F}$ & 5.1 & Right & NA & V600E Mutation & Normal \\
\hline 11. & $31-40$ & $\mathrm{~F}$ & 3.4 & Left & NA & V600E Mutation & Normal \\
\hline 12. & $1-10$ & M & 1.7 & Right & $46, X Y, t(9 ; 15)(p 24 ; q 24), \operatorname{inv} .(12)(q 13 q 15)$ & Wild type & Fusion Present \\
\hline 13. & $1-10$ & M & 1.5 & Right & NA & V600E Mutation & Normal \\
\hline 14. & $31-40$ & M & 4.3 & NA & NA & V600E Mutation & Normal \\
\hline 15. & $11-20$ & M & 7 & Right & NA & Wild type & Normal \\
\hline 16. & NA & NA & NA & NA & NA & Wild type & Normal \\
\hline 17. & $51-60$ & $\mathrm{~F}$ & NA & Left & NA & Wild type & Normal \\
\hline 18. & $51-60$ & $\mathrm{~F}$ & 5 & NA & NA & Uninformative & Uninformative \\
\hline 19. & $71-80$ & M & 1.8 & Right & NA & Wild type & Normal \\
\hline 20 & $21-30$ & $\mathrm{~F}$ & 2 & NA & NA & Wild type & Uninformative \\
\hline 21. & $61-70$ & $\mathrm{~F}$ & 4 & NA & NA & Wild type & Uninformative \\
\hline 22. & $71-80$ & $\mathrm{~F}$ & 2.5 & NA & NA & V600E Mutation & Normal \\
\hline 23. & $51-60$ & $\mathrm{~F}$ & 5 & NA & NA & Uninformative & Uninformative \\
\hline 24. & $51-60$ & $\mathrm{~F}$ & 3 & NA & NA & V600E Mutation & Normal \\
\hline 25. & $11-20$ & $\mathrm{~F}$ & 3 & Right & NA & V600E Mutation & Normal \\
\hline 26. & $41-50$ & $\mathrm{~F}$ & 1.5 & NA & NA & V600E Mutation & Uninformative \\
\hline 27. & $61-70$ & M & 8 & NA & NA & V600E Mutation & Normal \\
\hline 28. & $61-70$ & M & 3 & NA & NA & V600E Mutation & Normal \\
\hline
\end{tabular}

${ }^{a}$ Abbreviations: NA indicates not available, FISH Fluorescent in situ hybridization

concurrent H\&E slide was stained and marked by a pathologist to delineate the area of tumor for analysis. Fluorescent in situ hybridization probes were purchased from BlueGnome (Illumina, Cambridge, United Kingdom) and Empire Genomics (Buffalo, NY, USA). Briefly, prepared slides from the tumor were placed in a Coplin jar with $40 \mathrm{~mL}$ of $2 \mathrm{XSSC} \mathrm{pH} 7.0$ at $37^{\circ} \mathrm{C}$ for $15 \mathrm{~min}$. Treatment of slides in 2XSSC was used to artificially age the chromosomes, making them less sensitive to overdenaturation. Next, the slides were dehydrated in 70,85 , and $100 \%$ ethanol at room temperature for $2 \mathrm{~min}$ each, followed by drying on a $50^{\circ} \mathrm{C}$ warmer for $15 \mathrm{~min}$. Paraffin embedded tissue slides were baked in a $60^{\circ} \mathrm{C}$ oven for a minimum of $1 \mathrm{~h}$. These slides were then placed on the VP processor (Abbott Molecular, Des Plaines, IL, USA) for de-paraffinization, pretreatment, and protease digestion. A mixture of $3.5 \mu \mathrm{l}$ of locus specific identifier
(LSI) hybridization buffer (Abbott Molecular, Des Plaines, IL, USA), $1 \mu \mathrm{l}$ of sterile water, and $0.5 \mu \mathrm{l}$ of probe was prepared for the BlueGnome probes and $4 \mu \mathrm{l}$ of Empire Genomics buffer was used with $1 \mu \mathrm{l}$ of probe for the Empire probes for each hybridization area. $5 \mu \mathrm{l}$ of probe mixture was applied to each hybridization area of patient and control slides. Prepared slides and probes were then co-denatured using the ThermoBrite machine at a denature temperature of $76^{\circ} \mathrm{C}$ for $5 \mathrm{~min}$ and then hybridized overnight. After hybridization, slides were washed using $40 \mathrm{ml}$ of $0.4 \mathrm{X}$ SSC/0.3\%NP40 for $2 \mathrm{~min}$, followed by $40 \mathrm{ml}$ of $2 \mathrm{X} \mathrm{SSC} / 0.1 \% \mathrm{NP} 40$ for $1 \mathrm{~min}$ to remove any excess or unbound probe. After slides were air-dried, $10 \mu \mathrm{l}$ of DAPI II counterstain on a $22 \times 22$ coverslip was applied to the targeted area of the slide.

FISH analysis was performed following standard techniques using a fluorescent microscope with appropriate 

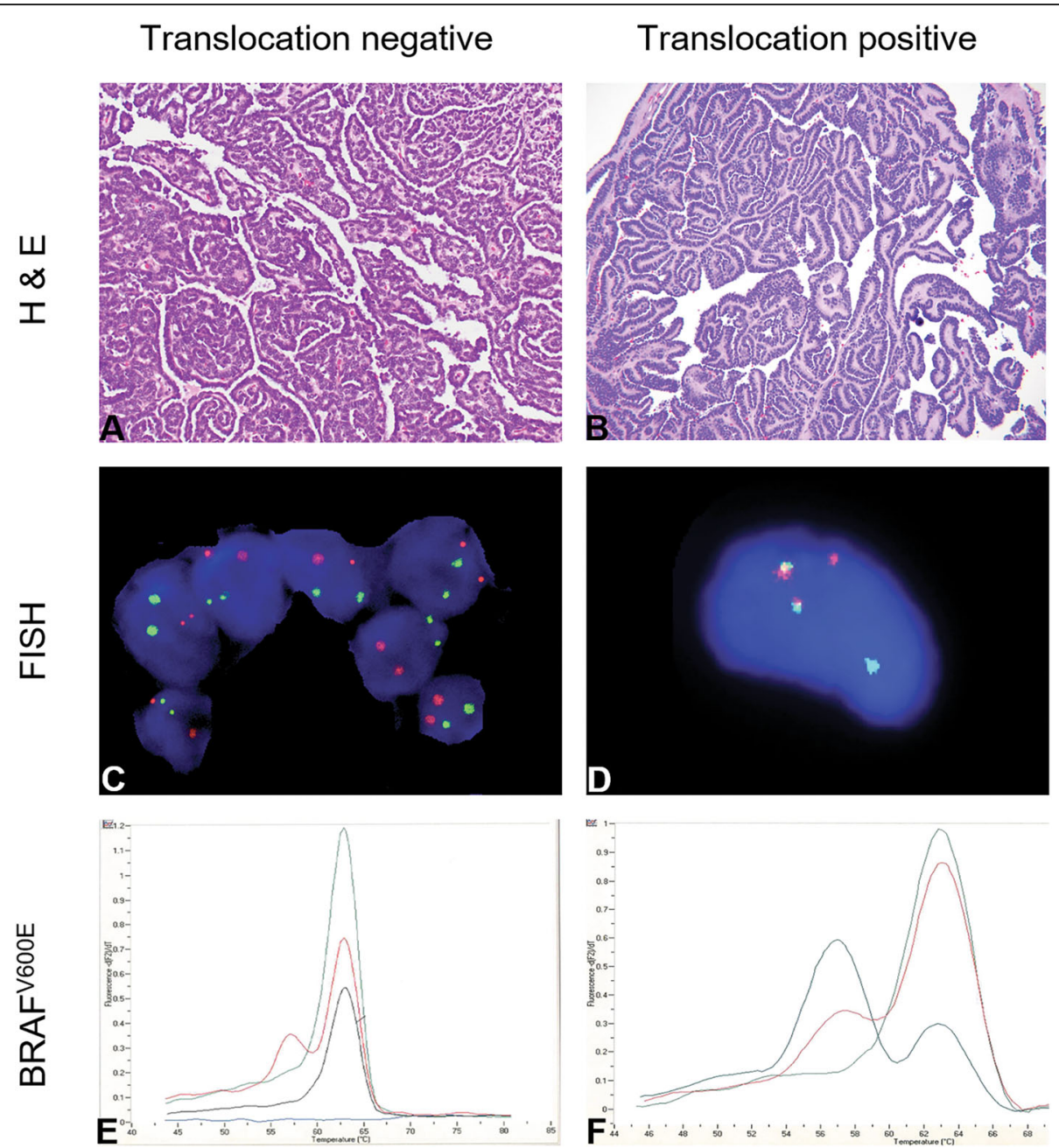

Fig. 1 Histologic, immunohistochemical, fluorescence in situ hybridization and molecular genetic analyses findings of metanephric adenoma. a Hematoxylin and eosin (H\&E) of translocation negative metanephric adenoma case, 200x total magnification $\mathbf{b}$ H\&E slide of translocation positive metanephric adenoma case, 200x total magnification c Fluorescence in situ hybridization with probes for chromosomes 9 (green signal) and 15 (orange/red signal) show normal nuclei with two red and two green signals, (original magnifications 100x) d Abnormal fluorescence in situ hybridization utilizing 2 color probes for the t(9;15) showing one green (9p24) and one orange/red (15q24) signal on the normal homologues. The yellow signals represent the fusion of the probes on the abnormal homologues of chromosome 9p24 and 15q24 (original magnifications 100x) e Melting curve analysis of BRAF mutations in metanephric adenoma sample illustrating a sample without a BRAF GTG > GAC (V600E) mutation of codon 600 (nucleotide 1799) f. Melting curve profiles illustrating the detection of a BRAF $F^{\mathrm{V} 600 \mathrm{E}}$ mutation of the metanephric adenoma sample with a GTG > GAC (V600E) mutation of codon 600 (nucleotide 1799). Green melting curve represents quality control (QC) wild-type (WT), red melting curve represents QC positive for $\mathrm{V} 600 \mathrm{E}$, black curve represents patient samples (E-non-mutated; F-BRAF ${ }^{\mathrm{V} 600 \mathrm{E}}$ mutated) are compared, additional melting peaks or changes in peak-area ratios indicate a sequence alteration under the probe (E and $F$ )

filters (Olympus, Tokyo, Japan). The number of hybridization signals for each probe was assessed on a minimum of twenty metaphases from fresh tumor slides and from 200 nuclei on the paraffin embedded tissue slides with strong and well-delineated signals, and were further selected for thorough examination using Applied Spectral Imaging (ASI) software (Carlsbad, CA, USA). Karyotypes were described and reported in accordance with the International System Committee for Human Cytogenomic Nomenclature (ISCN) 2016 [22].
Probes used to interrogate the $\mathbf{9 q} 24$ region were: RP11-143 M15 (9p24.3-green), RP11-59O6 (9p24.3-orange), RP11-130C19 (9p24.3-green), and RP11-1107A23 (9p24.3-green). Probes used to interrogate the $\mathbf{1 5 q} 24$ region were: RP11-62D2 (15q25.3-orange) and RP11608H9 (15q25.3-orange).

\section{BRAF mutation analysis}

FFPE sections were evaluated for the BRAF mutation on a Roche LightCycler 2.0 instrument (Mannheim, Germany) utilizing the allelic discrimination by real time 


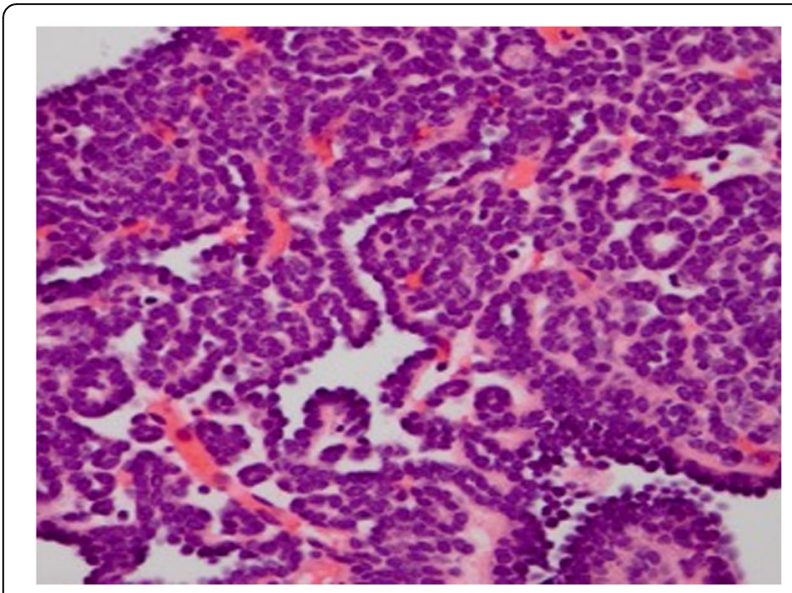

Fig. 2 Hematoxylin and eosin photomicrograph of BRAF wild type case, showing classic features of renal metanephric adenoma. Small cells with a high nuclear to cytoplasmic ratio form small tubules, rudimentary intraluminal buds and sheets

polymerase chain reaction (PCR), which was performed at the Clinical Laboratory Improvements Amendments (CLIA) certified ACL Laboratories (Rosemont, IL, USA). In short, the appropriate FFPE tissue block was selected by the pathologist. Four-micrometer-thick sections from FFPE tissue blocks were enriched by manual microdissection and DNA was isolated by the ZymoPinPiont method (Irvine, CA, USA), according to the manufacturer's protocol. Exon 15 of the BRAF gene was amplified from $50 \mathrm{ng}$ of genomic DNA by real time PCR using sequence specific primers ordered from Invitrogen-Life Technologies (Carlsbad, CA, USA) (forward primer: $5^{\prime}$ CTCTTCATAATGCTTGCTCTGATAGG-3', and reverse primer: 5'-TAGTAACTCAGCAGCATCTCAGG$\left.3^{\prime}\right)$. Melting curve analysis was performed by optimized fluorescent probes 5'-FL-TGGAGTGGGTCCCATCAG TTTGAACAGTTGTCTGGATCCATT SpacerC35'TGGTCTAGCTACAGTGAAATCTC-LC640. The PCR products were amplified in the following conditions: initial denaturation at $95^{\circ} \mathrm{C}$ for $10 \mathrm{~min}$; amplification $45 \mathrm{cy}$ cles of $95^{\circ} \mathrm{C}$ for $5 \mathrm{~s}, 60^{\circ} \mathrm{C}$ for $10 \mathrm{~s}$, and $72^{\circ} \mathrm{C}$ for $20 \mathrm{~s}$; melting curves 1 cycle of $95^{\circ} \mathrm{C}$ for $2 \mathrm{~min}, 40^{\circ} \mathrm{C}$ for 2 min, and $85^{\circ} \mathrm{C}$ at $5 \mathrm{~s}$; and cooling period of 1 cycle at
$40{ }^{\circ} \mathrm{C}$ for $30 \mathrm{~s}$. The method of BRAF exon 15-mutation analysis interpretation has been previously described [4, $11,14]$. Specifically, our assay detects 28 nucleotide changes involving the following codons: V600E, M, L, R, Q, D, K, A and G, L597V, S, Q, R and L, K601E, del, and N, A598V, A598_T599insV, T599I, T599_V600insT, T599_V600insTT, and V600_K601 > E.

Fisher's exact analysis was performed for comparison between the differential prevalence of $\mathrm{BRAF}^{\mathrm{V} 600 \mathrm{E}}$ mutation in patients under the age of 30 and those patients over 30 years of age. A $p$ value $<.05$ was used to indicate statistical significance.

\section{Results}

We analyzed 28 MAs. Among those, there were 17 women, 10 men and 1 unknown (F:M, 1.7:1). Patient age ranged from 9.8 to 73 years with median age of 52.5 years (52 among women; and 53.5 among men). Twenty patients were over the age of 30 , while 7 were under the age of 30 and 1 patient was of unknown age (Table 1 and Table 2). Tumor size ranged from $0.5 \mathrm{~cm}$ to $12 \mathrm{~cm}$ with a median size of $3 \mathrm{~cm}$. Patient cohort and clinical characteristics are summarized in Table 1.

Out of 28 cases studied, cytogenetic analysis was available in only six (21\%) cases, Table 2 . Three $(50 \%)$ cases out of 6 exhibited chromosomal aberration. All three patients were under the age of 30 . Two cases exhibited translocation involving chromosome 9 (9p24) and chromosome 15 (15q24), or t (9;15)(p24;q24) [11, 13]. To rule out constitutional abnormality in these two patients, peripheral blood samples revealed normal karyotypes $[11,13]$. One additional case that was translocation positive exhibited a translocation involving chromosome 6 (6q26) and chromosome 22 (q11.2) with a karyotype of 46,XX,t (6;22)(q26;q11.2). For this case, it is unknown if any genes are affected and if constitutional chromosome analysis was performed to rule out constitutional abnormality. The remaining three tumor cases demonstrated normal karyotypes of $46, \mathrm{XX}$ or $46, \mathrm{XY}$ and were over the age of 30 . There were no differences noted among genders. Cytogenetic results are further summarized in Table 2.

Table 2 Summary of cytogenetic and molecular findings

\begin{tabular}{|c|c|c|c|c|c|}
\hline \multirow[t]{2}{*}{ Total \# of cases } & \multirow{2}{*}{$\begin{array}{l}\text { Patients } \\
28\end{array}$} & \multirow{2}{*}{$\begin{array}{l}\text { Karyotype } n=28 \\
6(21 \%)\end{array}$} & \multicolumn{2}{|c|}{$B R A F^{\mathrm{V} 600 \mathrm{E}} n=24(\%)$ Mutation Wild Type } & \multirow{2}{*}{$\begin{array}{l}\text { FISH for } t(9 ; 15) n=20(\%) \\
2(10 \%)\end{array}$} \\
\hline & & & $15(62 \%)$ & $9(38 \%)$ & \\
\hline$>30$ years & 20 & 3 & 13 & 3 & 0 \\
\hline$<30$ years & 7 & 3 & 2 & 5 & $2(100 \%)$ \\
\hline Unknown & 1 & 0 & 0 & 1 & \\
\hline Female (median age in years) & $17(52)$ & 3 & 8 & 5 & 1 \\
\hline Male (median age in years) & $10(53.5)$ & 3 & 7 & 3 & 1 \\
\hline Unknown & 1 & 0 & 0 & 1 & 1 \\
\hline
\end{tabular}




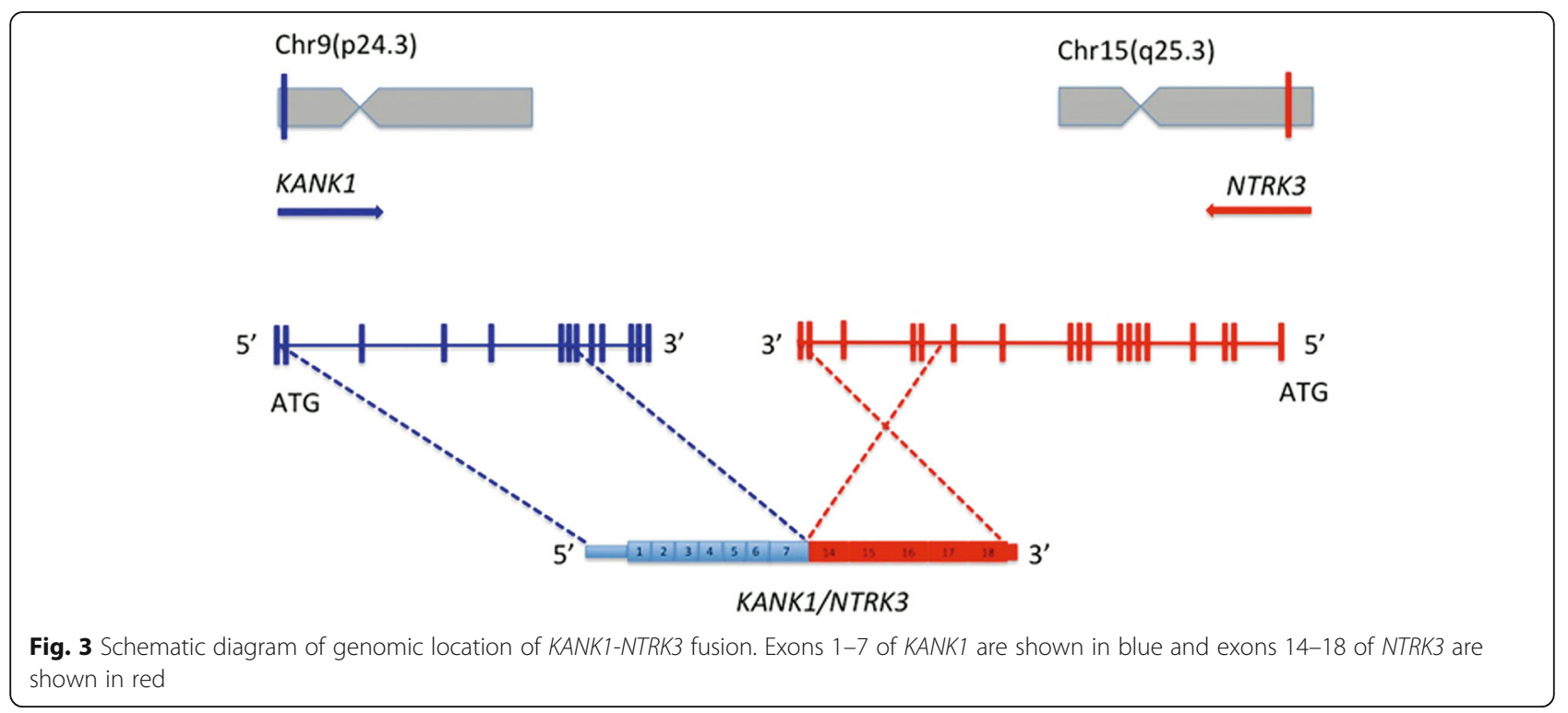

The focus of the study was to determine the frequency of $\mathrm{t}(9 ; 15)$ or KANK1-NTRK3 gene fusion using FISH, Fig. 1, C and D. Cases 1 through 9 were tested using FISH probes RP11-130C19 on 9p24.3 (green signals) and RP11-62D2 on 15q25.3 (orange signals) from
BlueGnome (Illumina, Cambridge, United Kingdom). Due to unavailability of previously used probes from BlueGnome, the following replacement probes were purchased from Empire Genomics (Buffalo, NY, USA): RP11-1107A23 on 9p24.3 (green signals) and RP11-

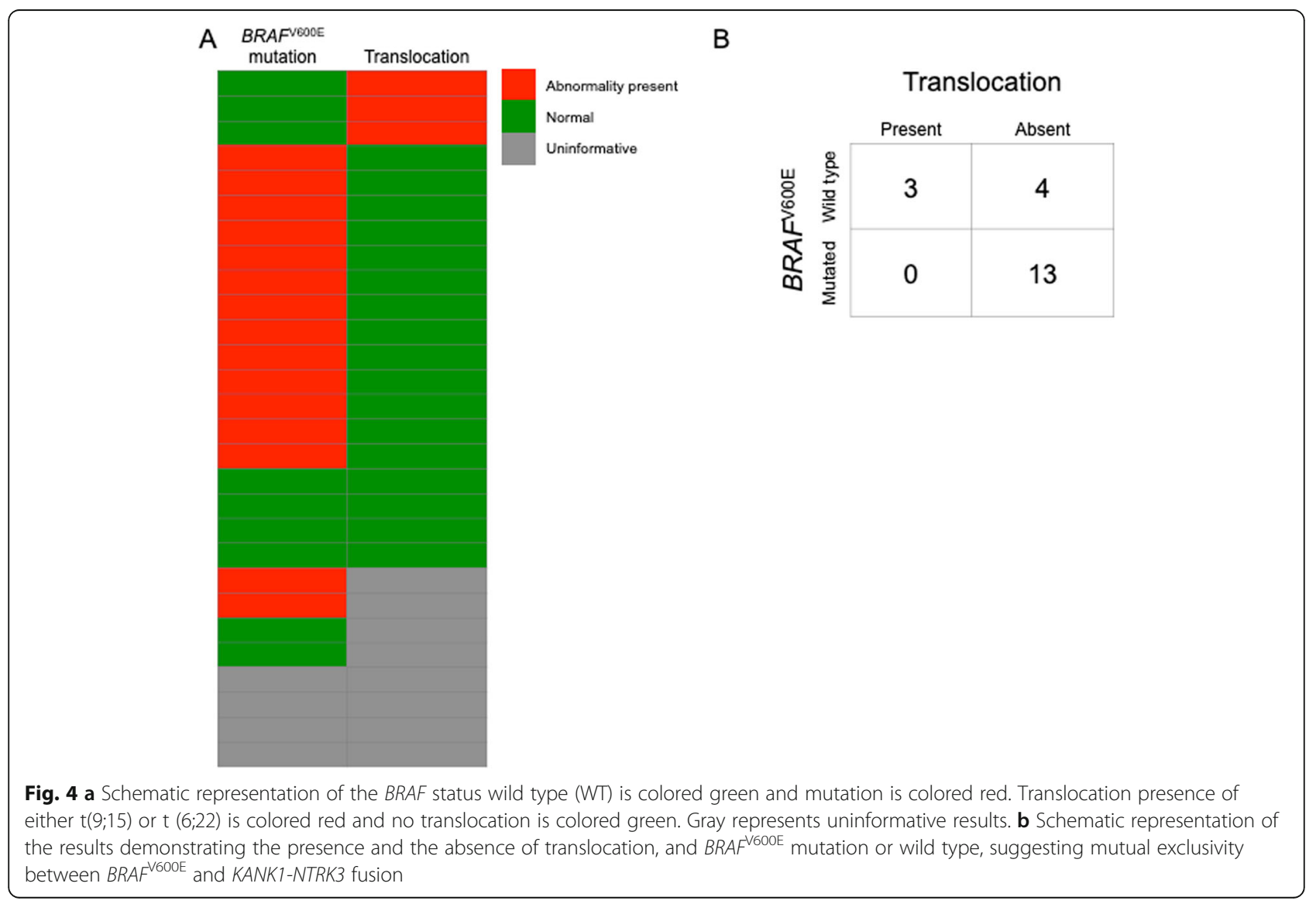


$608 \mathrm{H} 9$ on 15q25.3 (orange signals). A clinical cytogeneticist picked the best replacement probes based on available data from the vendor as well as University of California Santa Cruz (UCSC) Genome Browser (Genome Build 38), making sure probes covered the genes of interest. FISH analysis of the remaining cases (10 through 28) was carried out using the Empire Genomics probes. Clear signals and reportable FISH results were obtained in $20(71 \%)$ cases. Of the 20 tumors with FISH results, two tumors (10\%) were positive for KANK1NTRK3 fusion (Fig. 1, D). These two cases were also found to harbor the same translocation $t(9 ; 15)(\mathrm{p} 24 ; \mathrm{q} 24)$ by conventional cytogenetics analysis [11, 13]. Thus, concordance between FISH testing and chromosome analysis evaluation for the detection of the rearrangement and involvement of KANK1-NTRK3 genes was $100 \%$ ( $2 / 2$ cases). The remaining 18 (90\%) tumors were negative for KANK1-NTRK3 fusion, Fig. 1d. FISH in eight tumors $(29 \%)$ was technically unsuccessful due to lack of hybridization signals and therefore uninformative. This was most likely due to DNA degradation in archival material, a conclusion supported by the fact that many of the same cases were uninformative for $B R A F$ by PCR. FISH results are summarized in Table 2.

Of the 28 cases studied, the $B R A F$ mutational analysis was informative in 24 cases (86\%), Fig. 1e and f. BRAF exon 15 analysis was wild type (WT) in 9/24 (38\%) cases (Fig. 1e) and mutated in 15/24 (62\%) of cases, (Fig. 1f). Patient cases exhibiting BRAF ${ }^{\mathrm{V} 600 \mathrm{E}}$ mutation 13 of 15 (87\%) were over the age of 30 . The patients exhibiting $B R A F$ wild type results were predominantly (5 of 9;56\%) under the age of 30 . The Fisher exact test statistic value is 0.026 . The result is significant at $p<.05$.

In the present study, the $t(9 ; 15)$ resulted in a KANK1NTRK3 fusion transcript in which the first seven exons of KANK1 are fused to exon fourteen of the NTRK3, Fig. 3.

Out of the 9 cases lacking BRAF mutation, 3 cases (33\%) exhibited chromosomal translocation. Four out of six $B R A F^{\mathrm{WT}}$ cases did not have cytogenetic results available, but showed normal FISH pattern for $\mathrm{t}(9 ; 15)$. The remaining 2 cases were uninformative by FISH. Overall, 13 of $20(65 \%)$ cases lacking $t(9 ; 15)$ harbored $B R A F^{\mathrm{V} 600 \mathrm{E}}$ mutations. There were no cases demonstrating both the translocation and $B R A F^{\mathrm{V} 600 \mathrm{E}}$ mutation, suggesting mutual exclusivity between $B R A F^{\mathrm{V} 600 \mathrm{E}}$ and KANK1-NTRK3 fusion, Fig. 4 ( $a$ and $b)$.

\section{Discussion}

Typically, straightforward cases of MA can be diagnosed solely based on histologic features. Challenging cases require additional diagnostic testing for distinction from malignant renal tumors. Cytogenetic analysis is laborintensive, expensive, and generally not performed as part of routine clinical practice in classification of MAs; therefore, only a handful of previous studies have reported chromosomal aberrations in MAs. Catic et al. and Rakheja et al., observed balanced translocation $\mathrm{t}(9$; 15)(p24;q24) [11, 13], while Lerut et al., reported the presence of the dual balanced translocation, $\mathrm{t}(1,22)(\mathrm{q} 22$; q13), and $t(15 ; 16)(q 21 ; p 13)$ [23]. However, several studies that have reported cytogenetic findings have reported normal karyotypes [23-30].

In this study, we confirm that a subset of biologically distinct MAs in younger patients $(<30$ yrs. of age) exhibit aberrant chromosomal translocations and do not harbor $B R A F$ mutations. The novel findings of our study are that the typical MAs which do not harbor BRAF mutations can demonstrate cytogenetic aberrations. Additional larger cohort studies are necessary to confirm and further elucidate the frequency of the cytogenetic aberrations found in this subset of MAs.

Unlike chromosome analysis data, FISH analysis and immunohistochemistry analyses on MA are more frequently performed and reported in the literature. Most reported FISH studies have been primarily focused on testing for trisomies of chromosome 7 and 17, and loss of $\mathrm{Y}$ chromosome. Brown et al., reported trisomies of chromosomes 7 and 17 and loss of $Y$ chromosome in eight of 11 cases classified as MA [31]. However, their eight cases almost certainly represented examples of solid variant of PRCC, an entity that was described in the literature subsequent to their publication [32-34]. Recent studies strongly recommend utilization of FISH analysis to aid in differentiating those cases that deviate from the expected immunohistochemical staining pattern $[3,4]$.

Recent studies of MA have emphasized the importance of advanced molecular testing. Previous studies have demonstrated that the vast majority of MAs harbor $B R A F$ ${ }^{\mathrm{V} 600 \mathrm{E}}$ mutations, and that epithelial WTs lack $B R A F^{\mathrm{V} 600 \mathrm{E}}$ mutations [19, 20, 35]. Choueiri et al. published the largest series of MA demonstrating that $90 \%$ of MAs harbor a $B R A F^{\mathrm{V} 600 \mathrm{E}}$ mutation [14]. This was the first large study to shed light on the molecular underpinnings of MA and to investigate $B R A F^{\mathrm{V} 600 \mathrm{E}}$ mutation in this indolent tumor. Additionally, they tested 129 non-MA renal neoplasms and detected BRAF V600E mutation in only one PRCC. Cytogenetic analysis of this PRCC case revealed the presence of trisomy of chromosomes 7 and 17. Padilha et al. and Choueiri et al. suggest that molecular $B R A F^{\mathrm{V} 600 \mathrm{E}} \mathrm{mu}$ tation analysis is a valuable diagnostic tool in the differential diagnosis of this rare kidney tumor that may be diagnostically challenging $[8,14]$.

More recently, Chami et al. studied pediatric MA cases for $B R A F^{\mathrm{V} 600 \mathrm{E}}$ mutations and found three out of four cases to be positive for $B R A F^{\mathrm{V} 600 \mathrm{E}}$ mutation; 10 cases of pediatric renal cell carcinoma and 10 cases of Wilms' tumor did not exhibit $B R A F^{\mathrm{V} 600 \mathrm{E}}$ mutation [6]. To date, there are no cases reported in literature of Wilms' tumor exhibiting BRAF mutations. 
Similarly, Udager et al. evaluated eleven MA cases for $B R A F^{\mathrm{V} 600 \mathrm{E}}$ mutations and found eight out of eleven cases to be positive for $B R A F^{\mathrm{V} 600 \mathrm{E}}$ mutation. Of the three cases negative for $B R A F^{\mathrm{V} 600 \mathrm{E}}$ mutation, two exhibited a novel $B R A F^{\mathrm{V} 600 \mathrm{D}}$ mutation, of which one had a compound $B R A F^{\mathrm{V} 600 \mathrm{D}}$ and $B R A F^{\mathrm{K} 601 \mathrm{~L}}$ mutation [4]. Overall, $90 \%$ of all published MA cases evaluated for $B R A F$ mutations harbor BRAF exon 15 mutations. Most recent published study by Chan et al. examined the genetic profiles using next-generation sequencing on eleven conventional MAs and revelated all eleven cases harboring $B R A F^{\mathrm{V} 600 \mathrm{E}}$ mutations [35].

Our assay, which is capable of detecting 28 different $B R A F$ mutations including $B R A F^{\mathrm{V} 600 \mathrm{D}}$ and $B R A F^{\mathrm{K} 601 \mathrm{~L}}$ only detected $B R A F^{\mathrm{V} 600 \mathrm{E}}$ mutations. Our results differ significantly from those in the literature in the overall lower frequency of $B R A F$ mutations (62\% vs. $90 \%)$. This may be due to the fact that in our study $25 \%$ of our patients were under the age of 30 . We observed a possible trend towards patients younger than 30 years-old showing $B R A F^{\mathrm{WT}}$ tumors. This data suggests that MA in younger patients may be genetically distinct from its counterpart in older patients, but a larger patient cohort is needed to confirm this observation.

Lastly, we compared $B R A F^{V 600 E}$ mutation analysis results with FISH for KANK1-NTRK3 gene fusion. Of the nine cases that exhibited $B R A F^{\mathrm{WT}}, 3$ cases were those that demonstrated chromosomal aberrations by conventional karyotyping. Of the three cases that showed chromosomal translocations, two were positive for $\mathrm{t}$ (9; $15)$ and KANK1-NTRK3 gene fusion by FISH. The remaining six $B R A F^{\mathrm{WT}}$ cases did not have conventional cytogenetic analyses. Four of these six cases were negative for KANK1-NTRK3 fusion by FISH, and 2 cases were uninformative. Overall, 13 of $20(65 \%)$ cases lacking $\mathrm{t}(9 ; 15)$ harbored $B R A F$ mutations. There were no cases with both $\mathrm{t}(9 ; 15)$ and $B R A F^{\mathrm{V} 600 \mathrm{E}}$ mutation suggesting exclusivity between $B R A F^{\mathrm{V} 600 \mathrm{E}}$ and $\mathrm{t}(9 ; 15)$ and that the latter may be the genetic event behind a subset of $B R A F^{\mathrm{WT}}$ MAs.

A significant limitation of our study is the retrospective nature of case series with inability to test the BRAFwild type cohort for additional mutations. Unfortunately, many cases had very little or no additional sample material to perform NTRK3, pan-Trk and BRAF immunohistochemistry testing.

\section{Conclusion}

In conclusion, we report KANK1-NTRK3 fusion without $B R A F^{\mathrm{V} 600 \mathrm{E}}$ mutation in two MA cases. This finding supports the initial suggestion that KANK1-NTRK3 is the pathogenetically significant fusion transcript in tumors carrying a t $(9,15)(\mathrm{p} 24 ; \mathrm{q} 24)$ and lacking $B R A F^{\mathrm{V} 600 \mathrm{E}} \mathrm{mu}-$ tation in younger patient cohort. In this study, we have provided additional evidence that metanephric adenomas have relatively noncomplex karyotypes and have distinctive cytogenetic profiles. The cytogenetic profile can be useful in resolving a differential diagnosis of metanephric adenoma.

Classic histopathological features of MA coupled with a documented BRAF ${ }^{\mathrm{V} 600 \mathrm{E}}$ mutation are diagnostic of MA; however, we and others have demonstrated that the absence of $B R A F^{\mathrm{V} 600 \mathrm{E}}$ mutation does not exclude a diagnosis of MA. For those case lacking BRAF mutations, alternative testing such as FISH analysis for KANK1NTRK3 fusion and/or cytogenetic chromosome analysis to look for $\mathrm{t}(9 ; 15)(\mathrm{p} 24 ; \mathrm{q} 24)$ may be warranted.

\section{Abbreviations \\ MA: Metanephric adenoma; FFPE: Formalin fixed paraffin-embedded; H\&E: Hematoxylin and eosin; WHO: World Health Organization; PRCC: Papillary renal cell carcinoma; WT: Wilms' tumor; ASI: Applied Spectral Imaging; ISCN: International System Committee for Human Cytogenomic Nomenclature; PCR: Real time polymerase chain reaction; CLIA: Clinical Laboratory Improvements Amendments}

\section{Acknowledgements}

We would like to thank Peter J. Socki, BS, HTL, ASCP and the technical staff at ACL Laboratories Cytogenetics Department (Rosemont, IL) for their excellent technical assistance, and the Advocate Lutheran General Hospital James R. \& Helen D. Russell Institute for Research and Innovation, Park Ridge, $\mathrm{IL}$ for their assistance in study design.

\section{Authors' contributions}

A.C. selected, directed, and reported testing, wrote manuscript. A.S. performed FISH analysis. L.M. performed BRAF mutation analysis. F.S., O. H, S.R., and D.R. provided us with FFPE samples, patient demographics and contributed their pathology expertise. A.K. designed figures and tables, and assisted in writing manuscript. J.K. and M.R.P. provided guidance and expertise in developing this study. All authors read and approved the final manuscript.

Funding

Not applicable.

\section{Availability of data and materials}

The data generated and/or analyzed during the current study is available from the corresponding author on reasonable request.

\section{Ethics approval and consent to participate}

No administrative permissions were required to access the raw data and specimens used in this study. All samples were de-identified and only relevant information pertaining to this study was shared. The need for consent to participate was also waived by the ethics committee at the Advocate Lutheran General Hospital James R. \& Helen D. Russell Institute for Research and Innovation. The ethics committee at the Advocate Lutheran General Hospital James R. \& Helen D. Russell Institute for Research and Innovation ruled that no formal ethics approval was required for this study.

Consent for publication

Not applicable.

Competing interests

All authors declare that they have no competing interests.

\section{Author details}

'Department of Cytogenetics, ACL Laboratories, Rosemont, IL, USA. ${ }^{2}$ Department of Genetics and Bioengineering, International Burch University, Francuske revolucije bb, Ilidza, 71000 Sarajevo, Bosnia and Herzegovina. ${ }^{3}$ Department of Clinical Pathology, Cytology and Human Genetics, Clinical Center of the University of Sarajevo, Sarajevo, Bosnia and Herzegovina. 
${ }^{4}$ Department of Pathology, Charles University Hospital Pilsen, Pilsen, Czech Republic. ${ }^{5}$ Department of Pathology, Saint Joseph Hospital, Denver, CO, USA. ${ }^{6}$ Department of Pathology and Pediatrics, University of Texas Southwestern Medical Center, Dallas, TX, USA. 'Departments of Pathology and Laboratory Medicine, Children's Health, Dallas, TX, USA. ${ }^{8}$ Department of Pathology, Advocate Lutheran General Hospital, Park Ridge, IL, USA. ${ }^{9}$ Department of Pathology, Chicago Medical School of Rosalind Franklin University of Medicine and Science, North Chicago, IL, USA. ${ }^{10}$ Advocate Medical Group Genetics, Park Ridge, IL, USA.

Received: 6 May 2020 Accepted: 9 October 2020

Published online: 12 October 2020

\section{References}

1. Grignon DJ, Eble J, Argani P, Hartmann A. Metanephric Tumours. In: Moch H, Humphry PA, Ulbright TM, Reuter VE, eds. World Health Organization classification of Tumours of the urinary system and male genital Organs, 4th ed. Lyon, France: IARC Press; 2016:45-47.

2. Argani P, Lee J, Netto GJ, Zheng G, Tseh-Lin M, Park BH. Frequent BRAF V600E mutations in Metanephric stromal tumor. Am J Surg Pathol. 2016:40: 719-22

3. Kinney SN, Eble JN, Hes O, et al. Metanephric adenoma: the utility of immunohistochemical and cytogenetic analyses in differential diagnosis, including solid variant papillary renal cell carcinoma and epithelialpredominant nephroblastoma. Mod Pathol. 2015;28:1236-48.

4. Udager AM, Pan J, Magers MJ, et al. Molecular and immunohistochemical characterization reveals novel BRAF mutations in metanephric adenoma. Am J Surg Pathol. 2015;39:549-57.

5. Li G, Tang Y, Zhang R, Song H, Zhang S, Niu Y. Adult metanephric adenoma presumed to be all benign? A clinic perspective. BMC Cancer. 2015:15:310.

6. Chami R, Yin M, Marrano P, Teerapakpinyo C, Shuangshoti S, Thorner PS. BRAF mutations in pediatric metanephric tumors. Hum Pathol. 2015;46: 1153-61.

7. Bruder E, Passera O, Harms D, et al. Morphologic and molecular characterization of renal cell carcinoma in children and young adults. Am J Surg Pathol. 2004;28:1117-32.

8. Mantoan Padilha M, Billis A, Allende D, Zhou M, Magi-Galluzzi C. Metanephric adenoma and solid variant of papillary renal cell carcinoma: common and distinctive features. Histopathology. 2013;62:941-53.

9. Pins MR, Jones EC, Martul EV, Kamat BR, Umlas J, Renshaw AA. Metanephric adenoma-like tumors of the kidney: report of 3 malignancies with emphasis on discriminating features. Arch Pathol Lab Med. 1999;123:415-20.

10. Blanco LZ Jr, Schein CO, Patel T, et al. Fine-needle aspiration of metanephric adenoma of the kidney with clinical, radiographic and histopathologic correlation: a review. Diagn Cytopathol. 2013;41:742-51.

11. Catic A, Kurtovic-Kozaric A, Johnson SH, Vasmatzis G, Pins MR, Kogan J. A novel cytogenetic and molecular characterization of renal metanephric adenoma: Identification of partner genes involved in translocation t $(9 ;$ 15)(p24; q24). Cancer Genet. 2017:214-5 9-15.

12. Catic A, Kurtovic-Kozaric A, Sophian A, et al. Prevalence of KANK1-NTRK3 fusion in renal metanephric adenomas that lack BRAF mutations. Cancer Genet. 2018:224-5 59 .

13. Rakheja D, Lian F, Tomlinson GE, Ewalt DH, Schultz RA, Margraf LR. Renal metanephric adenoma with previously unreported cytogenetic abnormalities: case report and review of the literature. Pediatr Dev Pathol. 2005:8:218-23.

14. Choueiri TK, Cheville J, Palescandolo E, et al. BRAF mutations in metanephric adenoma of the kidney. Eur Urol. 2012;62:917-22.

15. Chappé C, Padovani L, Scavarda D, et al. Dysembryoplastic neuroepithelial tumors share with pleomorphic xanthoastrocytomas and gangliogliomas BRAF(V600E) mutation and expression. Brain Pathol. 2013;23:574-83.

16. Brastianos PK, Taylor-Weiner A, Manley PE, et al. Exome sequencing identifies BRAF mutations in papillary craniopharyngiomas. Nat Gene. 2014; 46:161-5.

17. Taube JM, Begum S, Shi C, Eshleman JR, Westra WH. Benign nodal nevi frequently harbor the activating V600E BRAF mutation. Am J Surg Pathol. 2009;33:568-71.

18. Olgac S, Hutchinson B, Tickoo SK, Reuter VE. Alphamethylacyl-CoA racemase as a marker in the differential diagnosis of metanephric adenoma. Mod Pathol. 2006;19:218-24.
19. Miao J, Kusafuka T, Fukuzawa M. Hotspot mutations of BRAF gene are not associated with pediatric solid neoplasms. Oncol Rep. 2004;12:1269-72.

20. Caliò A, Eble JN, Hes O, et al. Distinct clinicopathological features in metanephric adenoma harboring BRAF mutation. Oncotarget. 2016;8: 54096-105.

21. Gattenlöhner S, Etschmann B, Riedmiller H, Müller-Hermelink HK. Lack of KRAS and BRAF mutation in renal cell carcinoma. Eur Urol. 2009:55:1490-1.

22. McGowan-Jordan J, Simons A, Schmid M, eds. ISCN 2016: an international system for human Cytogenomic nomenclature (2016). Basel, Switzerland: S. Karger; 2016.

23. Lerut $\mathrm{E}$, Roskams $\mathrm{T}$, Joniau $\mathrm{S}$, et al. Metanephric adenoma during pregnancy: clinical presentation, histology, and cytogenetics. Hum Pathol. 2006;37: 1227-32.

24. Jones EC, Pins M, Dickersin GR, Young RH. Metanephric adenoma of the kidney. A clinicopathological, immunohistochemical, flow cytometric, cytogenetic, and electron microscopic study of seven cases. Am J Surg Pathol. 1995;19:615-26.

25. Brisigotti M, Cozzutto C, Fabbretti G, Sergi C, Callea F. Metanephric adenoma. Histol Histopathol. 1992;7:689-92.

26. Granter SR, Fletcher JA, Renshaw AA. Cytologic and cytogenetic analysis of metanephric adenoma of the kidney: a report of two cases. Am J Clin Pathol. 1997:108:544-9.

27. Gatalica Z, Grujic S, Kovatich A, Petersen RO. Metanephric adenoma: histology, immunophenotype, cytogenetics, ultrastructure. Mod Pathol. 1996;9:329-33

28. Tsuji M, Murakami Y, Kanayama HO, Sano T, Kagawa S. A case of renal metanephric adenoma: histologic, immunohistochemical and cytogenetic analyses. Int J Urol. 1999;6:203-7.

29. Renshaw AA, Freyer DR, Hammers YA. Metastatic metanephric adenoma in a child. Am J Surg Pathol. 2000;24:570-4.

30. Kohashi K, Oda Y, Nakamori M, et al. Multifocal metanephric adenoma in childhood. Pathol Int. 2009;59:49-52.

31. Brown JA, Sebo TJ, Segura JW. Metaphase analysis of metanephric adenoma reveals chromosome $Y$ loss with chromosome 7 and 17 gain. Urology. 1996:48:473-5.

32. Brunelli M, Eble JN, Zhang S, Martignoni G, Cheng L. Metanephric adenoma lacks the gains of chromosomes 7 and 17 and loss of $Y$ that are typical of papillary renal cell carcinoma and papillary adenoma. Mod Pathol. 2003;16: 1060-3.

33. Pan CC, Epstein Jl. Detection of chromosome copy number alterations in metanephric adenomas by array comparative genomic hybridization. Mod Pathol. 2010:23(12):1634-40.

34. Kuroda K, Hiroi M, Toi M, Enzan H. Review of metanephric adenoma of the kidney with focus on clinical and pathobiological aspects. Histol Histopathol. 2003;18(1):253-7.

35. Chan E, Stohr B, Croom N et al. Molecular characterization of metanephric adenomas beyond BRAF: genetic evidence for potential malignant evolution. Histopathol. 2020;76:1084-90.

\section{Publisher's Note}

Springer Nature remains neutral with regard to jurisdictional claims in published maps and institutional affiliations.

Ready to submit your research? Choose BMC and benefit from:

- fast, convenient online submission

- thorough peer review by experienced researchers in your field

- rapid publication on acceptance

- support for research data, including large and complex data types

- gold Open Access which fosters wider collaboration and increased citations

- maximum visibility for your research: over $100 \mathrm{M}$ website views per year

At BMC, research is always in progress.

Learn more biomedcentral.com/submission 